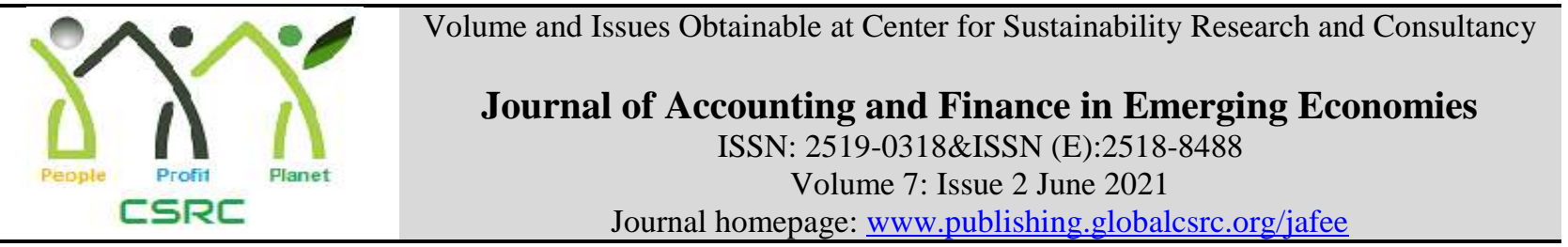

\title{
The Impact of Behavioral Finance Factors and the Mediating Effect of Investment Behavior on Individual's Financial Well-being: Empirical Evidence from Pakistan
}

\author{
* Muhammad Arsalan Ali, Khwaja Fareed University of Engineering and Information \\ Technology Rahim Yar Khan, Pakistan \\ Khalil ur Rehman, Khwaja Fareed University of Engineering and Information Technology \\ Rahim Yar Khan, Pakistan \\ Adnan Maqbool, Khwaja Fareed University of Engineering and Information Technology \\ Rahim Yar Khan, Pakistan \\ Shahid Hussain, Khwaja Fareed University of Engineering and Information Technology \\ Rahim Yar Khan, Pakistan \\ *Corresponding author's email: arsalan61842@ gmail.com
}

\begin{tabular}{l}
\hline ARTICLE DETAILS \\
\hline History \\
Revised format: May 2021 \\
AvailableOnline: Jun 2021 \\
\\
\hline Keywords \\
Financial literacy, \\
Investment behavior, \\
Financial well-being, \\
Risk perception, \\
Risk tolerance, \\
\hline
\end{tabular}

JEL Classification

G4,G41

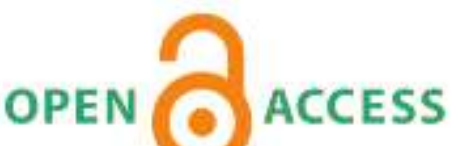

ABSTRACT

Purpose: Individual's financial well-being is recognized as a major concern for the general welfare and social welfare of society. In this context, it is very important to understand how people can ensure good financial well-being. This article aims to explore the effects of financial literacy, risk tolerance, and risk perception on the financial well-being of individuals, with an emphasis on behavioral investment interventions.

Design/Methodology/Approach: Quantitative research methods are used to measure the factors that affect financial well-being. A questionnaire was developed on Google Forms to collect data from people who have bank accounts. The sample of 318 Pakistanis supports the proposed hypothesis. Structural equation modeling (SEM) was used to evaluate the results.

Findings: The results show that risk tolerance, risk perception, and financial literacy influence people's investment behavior and ultimately their financial well-being. Individual financial behavior needs to be improved.

Implications/Originality/Value: In this context, there is an urgent need for financial education programs in the education system and centers of employment, behavioral development, and financial literacy. Future research on this topic could benefit from collecting longitudinal data which could provide more relevant information for Pakistanis seeking to achieve better financial well-being. All measures used are reported separately and individually, measuring the risk that respondents will misinterpret questions and even interpret their behavior.

(C) 2021 The authors, under a Creative Commons AttributionNonCommercial 4.0 
Recommended citation: Ali, M. A., Rehman, K., Maqbool, A. and Hussain, S. (2021). The Impact of Behavioral Finance Factors and the Mediating Effect of investment behavior on Individual's Financial Well-being: Empirical Evidence from Pakistan. Journal of Business and Social Review in Emerging Economies, 7 (2), 325-336.

\section{Introduction}

The financial situation is expressed in terms of income. Individuals are classified as insured when the income level is normal. On the other hand, for the median and poor financial situation is changed because they cannot meet their expenses due to low income (Michael Collins \& Urban, 2020). These measures do not determine FWB and, how well people handle financial resources or how much financial pressure they are under. Financial well-being changes the attitude of people who work freely to make decisions about financial progress (Brüggen et al., 2017). Moreover, Financial well-being, financial literacy, risk tolerance, and risk perception that have a positive relationship with each other, we evaluate all related factors affecting financial well-being in this study. However, financial literacy is becoming increasingly important in financial markets and plays an important role in developing scenarios for making financial decisions (Csorba, 2020). Financial markets are riskier, making decisions about financial transactions very difficult. Hence, financial literacy is necessary to build and improve your business. (Bhabha et al., 2014) Previous studies have frequently examined the relationship between FWB and financial literacy often referred by researchers and other predictors or precursors at the individual level (Brüggen, Hogreve, Holmlund, Kabadayi\&Löfgren, 2017). Kabadayi\& O'Connor, 2019). Financial literacy is seen as a major tool for increasing financial literacy rate but it has an optimistic impact on changing consumer behavior and financial well-being for low-income and marginalized populations (Lynch Jr and Netemeyer, 2014; Kaiser \& Menkhoff, 2017).

This study aims to fill the gap in the existing literature. Under the theoretical lens of Goyal \& Kumar, (2020) planned behavior theory (TPB) \& the happiness model (Salignac et al., 2020).In this regard, the paper explores how individuals' financial literacy, risk perception, and investment behaviors influence their financial wellbeing. The previous investigation study shows that how risk tolerance and risk perception influence investment behavior (Nguyen et al., 2019). Previous literature on this topic recognized the value of an individual's FWB towards financial literacy (Mahendru, 2020:Fu, 2020). Likewise, financial literacy, along with an individual's investment behavior (Bhabha et al., 2014), can also influence financial well-being (Rehman et al., 2019). In this connection, the literature stream does analyze various socio-economic behaviors and demographic factors that influence risk tolerance (Bayar et al., 2020). From understanding the literature, the role of risk tolerance and risk perception in financial well-being remains largely unexplored. This study adds an intermediate effect to investment behavior and in particular adds two factors: risk tolerance and risk perception, which influence financial well-being.

Additionally, previous research on this issue lacks empirical analysis. This study uses the structural equation modeling (SEM) technique to complete the analysis (Gerrans et al., 2014). The reason of this article is to fill the gap in exiting literature. For this purpose, demographic variables such as age, gender, occupation, income, and place of residence are used as control variables and two additional variables, namely risk tolerance and risk perception as independent variables and investment behavior as mediators between these variables, financial literacy, and financial well-being.

There are many empirical studies on financial well-being in developed countries. However, few studies are available in Pakistan that studies the factors that influence financial well-being. This document aims to achieve this main objective. It has four main objectives: First, to study the impact of financial literacy on financial well-being. Second, measuring the impact of investment 
behavior on financial well-being. Third, to find the relationship between risk tolerance, risk perception, and financial well-being.

This study pays good attention towards FWB and, contributes to the exiting literature in many ways. First, while previous research has explored the direct relationship between several model variables, it neglects the mediation effects to explain the processes by which people achieve FWB. By proposing a causal model, this article examines the main process by which Individuals with high financial literacy enjoy better financial well-being. In this way, This study increases the understanding of how individuals with high financial literacy show positive investment behavior and how individuals with positive investment behavior enjoy better financial well-being. To understand the effect of risk tolerance and risk perception on financial well-being, this study describes the various factors of FWB. However, this is an imperative addition to the exiting literature. Apart from the lack of researches on FWB and past events mentioned above in the Pakistani population sample provides an interesting perspective for analyzing this problem for the reasons given above.

Section 2 of the study consists of reviewing the relevant literature and developing hypotheses. Section 3 describes the variables and methods used in this study. Section 4 contains research results and critical discussion of specific literature. The final section concludes the study and describes the limitations and guidelines for future research.

\section{Literature Review}

In this section, we review the existing literature on financial literacy, investment behavior, risk tolerance, risk perception, and financial well-being. On this basis, we develop specific hypotheses for further testing.

\section{Financial literacy and Financial Well-being}

Financial well-being is described as financial wealth. Recognizes financial well-being as a function of the material and spiritual aspects of one's financial situation and defines FWB as an individual's feeling of satisfaction with their financial situation (Hayhoe et al., 2000). According to Joo \& Garman. (1998)Financial well-being is an Individual's attitude towards financial conditions based on objective aspects and evaluating them according to standards. Likewise Joo\& Garman. (1998) describe the concept of financial well-being, or in other words, individual perceptions of FWB vary depending on changes in an individual's living standards. In the past, welfare meant general happiness or satisfaction with their financial situation or wealth.

However, a variety of definitions of financial literacy are existing in the literature. Garman et al. (2000) define financial literacy as an understanding of the principles and terminology needed to successfully address personal finance problems. Jacob et al. (2000) view personal financial knowledge as a skill and information concept for personal financial management.

An assessment of the available literature will provide evidence of a positive relationship between financial literacy and financial well-being. It is also clear that financial literacy can influence financial decision-making in supporting research (Taft et al., 2013), which has a significant correlation with financial well-being. Based on these findings, it is said that because of high financial literacy, people who have valuable solutions also enjoy better financial well-being. Hence, the following hypothesis was developed:

H1: Individuals with high financial literacy enjoys better financial well-being

\section{Investment behavior and Financial Literacy}

The way an investor assesses, forecasts, analyzes, and reviews the decision-making process, 
including investment psychology, gathering, and understanding information, research, and analysis. This whole process is referred to as "investment behavior" (Gardel Vicente et al., 2010). Besides, the positive association between financial literacy and investment behavior is clear. It is also evident that financial literacy can influence investment decisions. The study by Bayar et al., (2020) identified a significant relationship between investment behavior and financial literacy. In the name of this result, it is said that people with high financial literacy have positive investment behavior and can make better investment solutions. Hence, the following hypothesis was developed:

H2: Individuals with High financial literacy exhibits positive investment behavior

\section{Investment Behavior and Financial well-being}

Investment behavior has a significant effect on financial well-being. How do individuals plan to make their financial arrangements, how much they will save money for the future, and how much they spend money on risky securities such as credit cards (Gutter \&Copur, 2011). Especially when it comes to investing, the way people manage their investments and, having an impact on their financial well-being. For example, behaviors like investing in financial stocks and EOBIs, etc., offsetting investments once a year, and investing in the retirement portfolio can be healthy for general financial well-being (Allgood \& Walstad, 2016). This premise argues that positive investment behavior can lead to better financial well-being, therefore it is believed that:

H3: Individuals with positive Investment behaviors enjoys better financial well-being

\section{Risk Tolerance and financial well-being}

Financial risk tolerance, which is defined as the maximum level of uncertainty that a person accepts in making financial decisions, extends to every part of economic and social life. While the value of assessing the financial risk tolerance is well documented, in practice the appraisal process is very difficult because of the subjective nature of risk (Carducci \& Wong, 1998). In the context of financial planning and financial advice, many empirical studies have been conducted to determine the determinants of an individual's financial risk tolerance because of their profound influence on financial investment decisions. The study by Castro-González et al., (2020) identified a significant consequence of risk tolerance on financial well-being. In addition, it also explains the effect of demographic variables such as age, gender, marital status, education, income, and place of residence on the RT. Moreover, these studies usually analyze personal qualifications, behavioral factors such as fear, life satisfaction, and a culture of risk tolerance. (Duasa\&Yusof, 2013; Fisher \& Yao, 2017; Irwin, 1993; Mishra \& Mishra, 2014; Rahmawati et al., 2015; Weber, 2014). Therefore it is assumed that:

H4: Individuals with high-risk tolerance have a significant impact on financial well-being

\section{Risk perception and financial well-being}

Perceptions of risk are beliefs about possible harm or possible harm. It is a subjective judgment that people make about the characteristics and severity of the risk (French et al., 2013).Early research uncovered variables in decision theory, such as probability (eg. Possible loss), outcome (e.g. profit yield, yield loss), volatility (e.g. return volatility) as the main factor affecting perceptions of financial risk (Mellers et al., 1992; Mellers and Chang, 1994; Koonce) et al., 2005).

H5: Individuals with higher risk perception affected positively on financial well-being Theoretical Framework:

The conceptual model above is mainly based on the theory of planned behavior (Ajzen 1991). This theory focuses on the well-known concept that explains the human actions motivation and 
abilities of individuals as predictors of their behavior decisions. Also, describe financial behavior such as saving or investing. According to TPB, human behavior is influenced by three basic concepts according to Ajzen (2002): behavioral beliefs, normative beliefs, and control beliefs. Beliefs about the likely outcome or other behavioral traits are called behavioral beliefs. Factors that can promote or exclude perceptions of behavior are known as control beliefs. The prior three points together lead to the formation of behavioral intentions, the relationship between financial well-being as a result of the conceptual model analysis leading to the happiness model (Lubomirski et al. 2005). This model concludes that an individual's level of happiness is influenced by three aspects: genetics, deliberate activity, and circumstances. Financial behavior is also understood as an activity where financial matters are scrutinized. In addition, long-term financial goals are an important factor in predicting individual happiness (Xiao et al. 2009).

\section{Conceptual Framework}

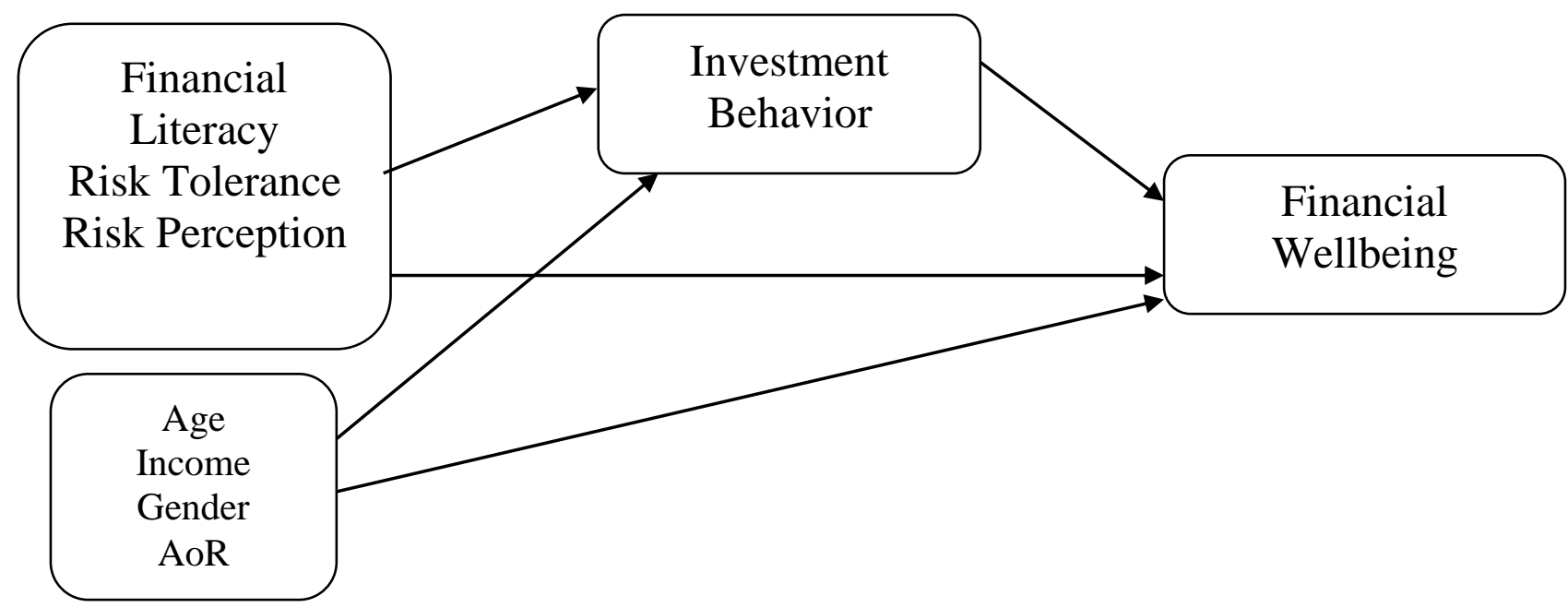

\section{Methodology Measures}

In this section, the methodology for conducting the study is presented. It includes the definition of sampling and data collection techniques. Given the nature of explanatory research, the philosophy of positivism studies was adopted. Quantitative research methods are used to measure financial literacy, risk tolerance, risk perception, investment behavior, and financial well-being. An online questionnaire on Google form was developed which is only intended for employees and having their own business. It is assumed that these people are mainly involved in financial decisions and have good financial knowledge. The sample must be representative of the intended population, but representation cannot be fully achieved because it is impossible to determine the similarity between the sample and the population (Pedhazur\&Schmelkin, 1991). Moreover, the data collected is not intended for use in the reference method and need not represent other variables of interest. In such cases, a homogeneous sample is seen as a requirement (Rust 
\&Golombok, 2009). Based on this premise, heterogeneous samples are seen as beneficial because they benefit from correlation studies (Pedhazur\&Schmelkin, 1991). For that reason, simple random sampling is considered appropriate. A sample size of 300 to 400 is considered suitable for social science perspective (Hair, Sarstedt, Ringle\& Mena, 2012). In this study, the sample size was set at 318 .

Table 1: Descriptive Statistics

\begin{tabular}{ccc}
\hline Age & Frequency & $\begin{array}{c}\text { Valid } \\
\text { Percent }\end{array}$ \\
\hline Less than 20 & 21 & 6.8 \\
$21-30$ & 43 & 13.8 \\
$31-40$ & 148 & 47.6 \\
$41-50$ & 62 & 19.9 \\
More than 50 & 37 & 11.9 \\
Total & 311 & 100.0
\end{tabular}

Gender

$\begin{array}{ccc}\text { Female } & 58 & 18.6 \\ \text { Male } & 253 & 81.4 \\ \text { Total } & 311 & 100.0\end{array}$

\section{Occupation}

$\begin{array}{ccc}\text { Business } & 153 & 49.2 \\ \text { Services (Job) } & 158 & 50.8 \\ \text { Total } & 311 & 100.0\end{array}$

\section{Education}

Non Formal Education $\quad 1 \quad .3$

Primary $\quad 3 \quad 1.0$

Secondary $\quad 20 \quad 6.4$

Graduate $\quad 158 \quad 50.8$

Post Graduate $\quad 110 \quad 35.4$

Doctorate $\quad 17 \quad 5.5$

Prefer not to say $\quad 2 \quad 6$

Total $\quad 311 \quad 100.0$

$\begin{array}{ccc}\text { Income } & & \\ \text { 5 lakhs per annum } & 103 & 33.1 \\ 5 \text { and 10 lakhs per annum } & 98 & 31.5 \\ 10 \text { and 15 lakhs per annum } & 47 & 15.1 \\ \text { 15 and 20 lakhs per annum } & 24 & 7.7 \\ \text { More than 20 lakhs per annum } & 16 & 5.1 \\ \quad \text { Prefer not to say } & 23 & 7.4 \\ \text { Total } & 311 & 100.0 \\ \text { Area of Residence } & & \\ \text { Rural } & 113 & 36.3 \\ \text { Urban } & 198 & 63.7 \\ \text { Total } & 311 & 100.0\end{array}$

There are six questions about demographics. Questions about financial literacy (05), investment behavior (06), risk tolerance (04), risk perception (04), and financial well-being (6) were taken from studies by (Rastogi \& Gupta, 2020:Klapper \& Lusardi, 2020: Rastogi \& Gupta, 
2020:Hoffmann et al., 2015)and CPFB-USA (2017), respectively. Considering employees and business owners with at least one year of work or business experience, the final sample consisted of 344 respondents. The response rate indicates that the sample is representative. The possibility of a significant bias in response can be minimized by achieving a high response rate.

To ensure validity and reliability, Collingridge's (2014) guidelines are followed. Questionnaire elements from studies by (Rastogi \& Gupta, 2020:Klapper \& Lusardi, 2020: Rastogi \& Gupta, 2020:Hoffmann et al., 2015)and CPFB-USA (2017) are discussed further by experts at Territory to ensure the validity of the person. Therefore, these questions are reformulated/amended by considering local attitudes.

Confirmatory factor analysis was performed for the constructive validity of the proposed hypothesis, as described by Atkinson et al. (2011). The results of the confirmatory factor analysis are shown in the given table. Based on the research hypothesis framework, four models for bestfit testing were developed. The RMSEA value of all models falls below 0.05 and is therefore considered very good. The CFI values of all models are above 0.90 and are therefore considered satisfactory.

\section{Data Analysis}

This section is about the findings of the study and their critical review regarding the paper.

\section{Hypothesis 1}

Hypothesis 1 was tested and the results are shown in the given table below. The model was considered suitable for evaluation, this can be seen from the goodness of fitness statistics in general, $\mathrm{P}>\mathrm{Chi} 2$ is equal to 0.000 . The results showed that financial literacy has a positive relationship with financial well-being. Individuals with high financial literacy enjoy better financial well-being. The probability of significance is 0.000 . The results of the model show that individuals who choose a business or services as a profession have a significant influence on the financial well-being of financial literacy with a p-value of 0.000 .

These results support the view of (Taft et al., 2013:Kamakia et al., 2017) which finds individuals who have a good financial literacy take financial wellbeing better and, individuals FWB that are consistently changed their logic and reasoning. Additionally, no statistically significant differences were found in the subgroups by demographic variables.

\section{Hypothesis 2}

Hypothesis 2 is estimated to ascertain the impact of financial literacy on investment behaviors. Structural Equation Modeling is executed and its results are presented in the given Table. It is found that financial literacy affects positively investment behavior, individuals having high financial literacy take their decisions better than others. The p-value of 0.000 identify the results as highly significant, overall, these findings suggest that financial literacy influence investment behavior positively. These results support the viewpoint of (Nguyen et al., 2019:Bayar et al., 2020:Hastings Olivia S Mitchell et al., 2011)

\section{Hypothesis 3}

Hypothesis 3 is assessed to examine the relationship between positive investment behavior and FWB. The results of structural equation modeling are shown in the given table, where it is known that investment behavior affects FWB at a significant p-value of 0.002 . The results suggest that a higher income can result in higher financial wealth. The results of this model show that people 
who become more involved in positive investment behavior enjoy better financial well-being. The relationship between positive investment behavior and financial well-being found in this model is in line with the empirical results of (Fazli et al., 2020:Taft et al., 2013:Awais, 2016)

\section{Hypothesis 4}

Hypothesis 4 was assessed to determine the relationship between risk tolerance and financial well-being. The SEM results are presented in a table. The relationship between risk tolerance and financial well-being was found to be significant. Individuals who have the knowledge to take risks can achieve better financial well-being. A p-value of 0.000 identifies an outcome of high significance. Risk tolerance is an important factor that affects various personal financial decisions (Elston, 2016:Grable, 2016). Overall, these results indicate that financial risk tolerance has a positive effect on FWB. These results support the view of (Castro-González et al., 2020:Gibson et al., 2013:Hoffmann et al., 2015)

\section{Hypothesis 5}

Hypothesis 5 was evaluated to determine the relationship between perceived risk and financial well-being. SEM results are shown in the table. The relationship between perceived risk and financial well-being is significant. People who have the knowledge to take high perceived risks can achieve better financial well-being. A p-value of 0.012 identifies a result of high significance, but our results support the opinion of (Nguyen et al., 2019:Slovic, 2016).

\section{Proposition 1}

It is assumed that this proposal defines the intermediary role of positive investment behavior between financial literacy, risk tolerance, and risk perception. The results estimated by structural equation modeling in Amos are shown in the table. The mediating role of investment behavior ( $\mathrm{p}-$ value $=0.00)$ is found in FL and FWB $(0,000)$, similar to risk tolerance, and the results of risk perception are also highly significant. These results indicate that risk tolerance and risk perception related to financial literacy have a significant impact on investment behavior and financial well-being. Therefore, it can be said that financial literacy, risk tolerance, and risk perception have a significant influence on financial well-being.

Table 2: Direct Results

\begin{tabular}{|c|c|c|c|c|c|c|c|}
\hline \multicolumn{3}{|c|}{ Variables } & Estimate & S.E. & C.R. & $\mathbf{P}$ & Label \\
\hline IB & $<---$ & $\mathrm{RP}$ & 0.182 & 0.052 & 3.513 & $* * *$ & par_46 \\
\hline IB & $<---$ & RT & 0.136 & 0.042 & 3.214 & 0.001 & par_47 \\
\hline IB & $<--$ & FL & 0.105 & 0.029 & 3.596 & $* * *$ & par_48 \\
\hline IB & $<---$ & Age & -0.08 & 0.034 & -2.328 & 0.02 & par_49 \\
\hline $\mathrm{IB}$ & $<---$ & Education & 0.088 & 0.044 & 1.982 & 0.047 & par_50 \\
\hline IB & $<---$ & Gender & -0.005 & 0.088 & -0.059 & 0.953 & par_51 \\
\hline IB & $<--$ & Area of Residence & 0.075 & 0.071 & 1.055 & 0.292 & par_52 \\
\hline IB & $<--$ & Income & -0.004 & 0.023 & -0.188 & 0.851 & par_53 \\
\hline IB & $<--$ & Occupation & -0.03 & 0.07 & -0.424 & 0.672 & par_54 \\
\hline FW & $<---$ & Income & 0.015 & 0.022 & 0.684 & 0.494 & par_37 \\
\hline FW & $<---$ & FL & 0.12 & 0.029 & 4.186 & $* * *$ & par_38 \\
\hline FW & $<--$ & $\mathrm{RT}$ & 0.25 & 0.041 & 6.081 & $* * *$ & par_39 \\
\hline FW & $<---$ & $\mathrm{RP}$ & 0.127 & 0.051 & 2.506 & 0.012 & par_40 \\
\hline FW & $<---$ & Age & 0.119 & 0.033 & 3.615 & $* * *$ & par_41 \\
\hline FW & $<--$ & Gender & -0.017 & 0.084 & -0.205 & 0.838 & par_42 \\
\hline
\end{tabular}




\begin{tabular}{cccccccc} 
FW & $<---$ & Education & -0.056 & 0.043 & -1.321 & 0.187 & par_43 \\
& & & & & & \\
FW & $<---$ & Area of Residence & 0.098 & 0.069 & 1.426 & 0.154 & par_44 \\
& & Occupation & 0.078 & 0.067 & 1.164 & 0.244 & par_45 \\
FW & $<---$ & IB & 0.172 & 0.054 & 3.152 & 0.002 & par_55 \\
FW & $<---$ & & & & & & \\
\hline
\end{tabular}

\section{Conclusions and Implications}

This article is based on the study of individuals' FWB in Pakistan. For this purpose, we have developed a conceptual model that examines various factors that are affecting the financial wellbeing of individuals.

To our knowledge, this study is the first attempt to examine the impact of risk perception and risk tolerance on an individual's FWB by collectively taking into account individual intentional interventions such as investment behavior. Therefore, this study addresses the importance to find out how individuals improve their investments and their FWB (Brüggen et al. 2017; Netemeyer et al. 2018).

Most of the empirical evidence supports the conceptual model proposed, as discussed in this study. It also provides support for theoretical frameworks. The combination of the TPB and the happiness model shows that both are seem sufficient to explain how Pakistanis achieve financial prosperity.

First, it is found that financial literacy is significantly associated with financial well-being. From this, we can conclude that financial literacy functions depending on the preference for making long-term planning in dealing with money. As far as we are concerned, this is one of the first studies to empirically show that risk perception and risk tolerance have a potential impact on people's financial well-being. Also, these results are in line with previous financial research which examines the significance of financial literacy and investment behavior which are positively related to financial well-being (Taft et al., 2013). Moreover, our results confirm that financial literacy is very effective for the financial welfare of society. In particular, we found that people with high financial literacy enjoyed better FWB.

Second, the outcome confirms that financial literacy has a positive impact on IB. Financially literate individuals can take their investment decisions better. The results are similar to prior studies (Fazli et al., 2020:Taft et al., 2013:Janor et al., 2016:Allgood \& Walstad, 2016:Awais, 2016:Nicolini \& Nicolini, 2019:Philippas \& Avdoulas, 2020).

Third, people with positive investment behavior enjoy better financial well-being. By emphasizing long-term financial goals, they enhance FWB and improve their actual investment behavior. Our results are similar to the general findings of prior studies, (Rehman et al., 2019:Fazli et al., 2020).

Fourth, as the proposed model shows, tolerance and perceptions of financial risk are closely related to an Individual's financial well-being. When people take more risks, they have a variety of positive behaviors, and these behaviors will bring them closer to financial satisfaction. (Castro-González et al., 2020:Klapper \& Lusardi, 2020:Nguyen et al., 2019). 
Fifth, it is found that higher risk perception is significantly associated with financial well-being. An individual taking higher risk perception enjoys better FWB. From this, we can conclude that with high RP individuals make better investment decisions and have a positive association with FWB.

Ultimately, the evidence shows the importance of the financial behavior of individuals that are comfortable with their financial position. In summary, our study provides an overview of the FWB as well as the degree of perceived behavior intention. Moreover, this study also explains the various financial interventions that affect an individual's FWB. Apart from the theoretical consequences discussed, these results also have practical consequences for financial behaviors.

The key findings of this study have significant results and implications. The results suggest that individual financial behavior should be improved. In this context, there is an urgent need for financial training programs in the education system and in work, centers to develop behavioral and financial literacy. In the case of Pakistan, where this type of programming is rare, this strategy implies shared responsibility between the government, the financial industry, and the people.

However, this document is not exempt from the limitation. First, the cross-section of the data makes it difficult to make the connections that are in the model. Future research on this topic could benefit from collecting longitudinal data, which will provide more relevant information for Pakistanis who are ready to achieve better financial well-being. Second, all measures used are reported separately and individually, measuring the risk that respondents will misinterpret questions and even interpret their behavior. In this way, future research could benefit from a combination of more objective and subjective measures. Third, although all elements add a reasonable measure to the scale and can be considered sufficient to measure any variable. Fourth, the use of secondary data may lead to actions that are not as complete as you would like them to be.

\section{References}

Allgood, S., \& Walstad, W. B. (2016). The effects of perceived and actual financial literacy on financial behaviors. Economic Inquiry, 54(1), 675-697. https://doi.org/10.1111/ecin.12255

Awais, M. (2016). International Journal of Economics and Financial Issues Impact of Financial Literacy and Investment Experience on Risk Tolerance and Investment Decisions: Empirical Evidence from Pakistan. International Journal of Economics and Financial Issues, 6(1), 7379. http:www.econjournals.com

Bayar, Y., Sezgin, H. F., Öztürk, Ö. F., \& Şaşmaz, M. Ü. (2020). Financial Literacy and Financial Risk Tolerance of Individual Investors: Multinomial Logistic Regression Approach. SAGE Open, 10(3). https://doi.org/10.1177/2158244020945717

Bhabha, J. I., Khan, S., Qureshi, Q. A., Naeem, A., \& Khan, I. (2014). Impact of Financial Literacy on Saving-Investment Behavior of Working Women in the Developing Countries. Journal of Finance and Accounting, 5(13), 118-123.

Brüggen, E. C., Hogreve, J., Holmlund, M., Kabadayi, S., \& Löfgren, M. (2017). Financial wellbeing: A conceptualization and research agenda. Journal of Business Research, 79, 228237. https://doi.org/10.1016/j.jbusres.2017.03.013

Carducci, B. J., \& Wong, A. S. (1998). Type A and risk taking in everyday money matters. Journal of Business and Psychology, 12(3), 355-359. https://doi.org/10.1023/A:1025031614989

Castro-González, S., Fernández-López, S., Rey-Ares, L., \& Rodeiro-Pazos, D. (2020). The 
Influence of Attitude to Money on Individuals' Financial Well-Being. Social Indicators Research, 148(3), 747-764. https://doi.org/10.1007/s11205-019-02219-4

Csorba, L. (2020). The determining factors of financial culture, financial literacy and financial behavior. Public Finance Quarterly, 65, 67-83. https://doi.org/10.35551/PFQ_2020_1_6

Elston, H. J. (2016). Risk tolerance. Journal of Chemical Health and Safety, 23(6), 1. https://doi.org/10.1016/j.jchas.2016.09.002

Fazli, M., Reza, T. S., \& Wijekoon, R. (2020). Financial Management, Savings Behavior, Investment Behavior and Financial Well-Being of Working Women in the Public Sector. 17(2), 135-153.

French, D. P., Darker, C. D., Eves, F. F., \& Sniehotta, F. F. (2013). The systematic development of a brief intervention to increase walking in the general public using an "extended" theory of planned behavior. Journal of Physical Activity and Health, 10(7), 940-948. https://doi.org/10.1123/jpah.10.7.940

$\mathrm{Fu}$, J. (2020). Ability or opportunity to act: What shapes financial well-being? World Development, 128, 104843. https://doi.org/10.1016/j.worlddev.2019.104843

Gardel Vicente, A., Munoz, I. B., Galilea, J. L. L., \& Del Toro, P. A. R. (2010). Remote automation laboratory using a cluster of virtual machines. IEEE Transactions on Industrial Electronics, 57(10), 3276-3283. https://doi.org/10.1109/TIE.2010.2041131

Gerrans, P., Speelman, C., \& Campitelli, G. (2014). The Relationship Between Personal Financial Wellness and Financial Wellbeing: A Structural Equation Modelling Approach. Journal of Family and Economic Issues, 35(2), 145-160. https://doi.org/10.1007/s10834013-9358-z

Gibson, R., Michayluk, D., \& Van de Venter, G. (2013). Financial risk tolerance: An analysis of unexplored factors. Financial Services Review, 22(1), 23-50. http://search.ebscohost.com/login.aspx?direct=true \&db=buh\&AN=87050291\&site=ehostlive\%5Cnhttp://content.ebscohost.com/ContentServer.asp?T=P\&P=AN\&K=87050291\&S= $\mathrm{R} \& \mathrm{D}=$ buh\&EbscoContent=dGJyMNXb4kSep7c4zOX0OLCmr0yep7VSsKe4SbCWxWXS \&ContentCustomer=dGJyMPGnr0+wqLdRu

Goyal, K., \& Kumar, S. (2020). Financial literacy: A systematic review and bibliometric analysis. International Journal of Consumer Studies, July, 1-26. https://doi.org/10.1111/ijcs.12605

Grable, J. E. (2016). Handbook of Consumer Finance Research. Handbook of Consumer Finance Research, 19-31. https://doi.org/10.1007/978-3-319-28887-1

Hastings Olivia S Mitchell, J. S., Chyn, E., Duarte, F., Fabregas, R., Frerichs, P., Fuentes, D., Johnston, S., Orellana, C., Luis Ruiz, J., Vásquez The authors thank David Bravo, J., Faibregas, R., \& Quijada, S. (2011). Nber Working Paper Series How Financial Literacy and Impatience Shape Retirement Wealth and Investment Behaviors.

Hayhoe, C. R., Leach, L. J., Turner, P. R., Bruin, M. J., \& Lawrence, F. C. (2000). Differences in spending habits and credit use of college students. Journal of Consumer Affairs, 34(1), 113133. https://doi.org/10.1111/j.1745-6606.2000.tb00087.x

Hoffmann, A. O. I., Post, T., \& Pennings, J. M. E. (2015). How Investor Perceptions Drive Actual Trading and Risk-Taking Behavior. Journal of Behavioral Finance, 16(1), 94-103. https://doi.org/10.1080/15427560.2015.1000332

Janor, H., Yakob, R., Hashim, N. A., Aniza, C., \& Wel, C. (2016). Financial literacy and investment decision in Malaysia and UK - Comparitive Study. Malaysian Journal of Society and Space, 2(2), 106-118.

Joo, S., \& Garman, E. T. (1998). Personal Financial Wellness May be the Missing Factor in Understanding and Reducing Worker Absenteeism. Personal Finance and Worker Productivity, 2(2), 172-182.

Kamakia, M. G., Mwangi, C. I., \& Mwangi, M. (2017). Financial Literacy and Financial Wellbeing of Public Sector Employees: A Critical Literature Review. European Scientific Journal, ESJ, 13(16), 233. https://doi.org/10.19044/esj.2017.v13n16p233

Klapper, L., \& Lusardi, A. (2020). Financial literacy and financial resilience: Evidence from 
around the world. Financial Management, 49(3), 589-614.

https://doi.org/10.1111/fima.12283

Mahendru, M. (2020). Financial well-being for a sustainable society : a road less travelled. https://doi.org/10.1108/QROM-03-2020-1910

Michael Collins, J., \& Urban, C. (2020). Measuring financial well-being over the lifecourse. European Journal of Finance, 26(4-5), 341-359. https://doi.org/10.1080/1351847X.2019.1682631

Nguyen, L., Gallery, G., \& Newton, C. (2019). The joint influence of financial risk perception and risk tolerance on individual investment decision-making. Accounting and Finance, 59(S1), 747-771. https://doi.org/10.1111/acfi.12295

Nicolini, G., \& Nicolini, G. (2019). Financial literacy and financial behavior. Financial Literacy in Europe, May, 85-140. https://doi.org/10.4324/9780429431968-3

Philippas, N. D., \& Avdoulas, C. (2020). Financial literacy and financial well-being among generation-Z university students: Evidence from Greece. European Journal of Finance, 26(4-5), 360-381. https://doi.org/10.1080/1351847X.2019.1701512

Rastogi, S., \& Gupta, S. (2020). Development of Scale to Measure Objectives-Oriented Investment Behavior. Journal of Behavioral Finance, 21(3), 301-310. https://doi.org/10.1080/15427560.2019.1692346

Rehman, K. U., Akhtar, H., \& Shah, S. Z. A. (2019). Framing Effect and Financial Wellbeing: Role of Investment Behaviors as Mediator. Review of Economics and Development Studies, 5(2), 343-354. https://doi.org/10.26710/reads.v5i2.555

Salignac, F., Hamilton, M., Noone, J., Marjolin, A., \& Muir, K. (2020). Conceptualizing Financial Wellbeing: An Ecological Life-Course Approach. Journal of Happiness Studies, 21(5), 1581-1602. https://doi.org/10.1007/s10902-019-00145-3

Slovic, P. (2016). The perception of risk. Scientists Making a Difference: One Hundred Eminent Behavioral and Brain Scientists Talk about Their Most Important Contributions, August, 179-182. https://doi.org/10.1017/CBO9781316422250.040

Taft, M. K., Hosein, Z. Z., \& Mehrizi, S. M. T. (2013a). The Relation between Financial Literacy, Financial Wellbeing and Financial Concerns. International Journal of Business and Management, 8(11). https://doi.org/10.5539/ijbm.v8n11p63

Taft, M. K., Hosein, Z. Z., \& Mehrizi, S. M. T. (2013b). The Relation between Financial Literacy, Financial Wellbeing and Financial Concerns. International Journal of Business and Management, 8(11), 63-75. https://doi.org/10.5539/ijbm.v8n11p63 